\title{
Las islas en un museo del continente. Colonialidad e imágenes del archipiélago de Juan Fernández JAVIERA CARMONA JIMÉNEZ
}

> Dra. en Historia. Facultad de Ciencias Sociales, Museo Universitario del Grabado - MUG, Universidad de Playa Ancha, Valparaíso, Chile javiera.carmons@upla.cl

ORCID 0000-0002-5519-416X

Universidad de Valparaíso

Facultad de Arquitectura

Revista Márgenes

Espacio Arte Sociedad

Las islas en un museo del continente. Colonialidad e imágenes del archipiélago de Juan Fernández Octubre 2021 Vol. $14 \mathrm{~N}^{\circ} 20$

Páginas 57 a 67

ISSN elec. 0719-4463

Recepción: Mayo 2021

Aceptación: Mayo 2021

doi.org/10.22370/marge-

nes.2021.14.20.3000

\section{RESUMEN}

El Archipiélago de Juan Fernández ha sido objeto de interés para las comunidades científicas, artísticas, literarias y museológicas, originando desde el continente programas epistémicos e incluso paradigmas culturales que conforman un sistema para pensar la geografía insular, sus temporalidades y sujetos. En este artículo se analizan las imágenes sobre Juan Fernández de la exhibición permanente del Museo de Historia Natural de Valparaíso, así como las pinturas sobre estas islas que son parte de la colección del museo. La narrativa visual insular se inscribe en un modelo de representación de la materialidad de los espacios insulares y los océanos como espacio negativo alrededor de los continentes. Las narrativas insulares en sus relaciones verbovisuales, lejos de ser periféricas en los procesos de conformación y consolidación de los nacionalismos y el Estado-nación moderno, desempeñan un rol significativo en la comprensión de la formulación de imaginarios nacionales.

\section{PALABRAS CLAVE}

isla / continente, visualidades, viajeros, naturalistas, colonialismo

\section{The islands in a museum of the continent. Coloniality and images of the Juan Fernández Archipelago}

ABSTRACT

The Juan Fernández Archipelago has been object of interest for the scientific, artistic, literary and museumlogical communities, originating from the continent epistemic programs and even cultural paradigms that form a system to think the insular geography, its temporalities and subjects. This article analyzes the images about Juan Fernández in the permanent exhibition of the Museum of Natural History of Valparaíso, as well as the engravings about these islands that are part of the museum's collection. The insular visual narrative is inscribed in a model of representation of the materiality of insular spaces and the oceans as negative space around the continents. The insular narratives in their verb-visual relations, far from being peripheral in the processes of conformation and consolidation of nationalisms and the modern nation-state, play a significant role in the understanding of the formulation of national imaginaries.

KEYWORDS

island / continent, visuality, travelers, naturalists, colonialism 


\section{INTRODUCCIÓN}

De acuerdo al Instituto Geográfico Militar (1998) el territorio insular de Chile está conformado por 3.739 islas, y la reflexión crítica sobre la comprensión de estos territorios, en el marco del desarrollo y consolidación del proyecto de estado-nación, se ha centrado en el Archipiélago de Chiloé (Montiel Vera, 2003; Mansilla, 2006, 2007; Pérez López, 2011; Ther, 2011, 2020) e Isla de Pascua (Campbell, 1999; Aguirre, 2003; Ferrando, Piergiova y Fuentes, 2011; Galilea, 2015), con énfasis en la historia política y literaria (Galindo, 2000). En esta misma línea de investigación, la Tierra del Fuego ha sido examinada en el eje isla/continente desde la observación de la continuidad de la cuadrícula urbana en la isla como extensión de una estructura urbana colonizadora del territorio y el paisaje (Espindola, 2018).

Se ha analizado y descrito el conjunto de representaciones producidas en el continente en torno al ambiente, al espacio y a la presencia humana (Horlent et al., 2020), y se han evaluado los mapas y fotografías del territorio como productores de un tejido de representación simbólica geopolítica a la vez reflexiva y performativa (Massotta, 2008). Finalmente, cabe mencionar el análisis de la representación en imágenes y asociaciones de la Tierra del Fuego a la sociedad estadounidense, ligada a la idea de paraíso, zona virgen, wilderness, referentes con los que se construyó la imagen mental de la nación chilena en el exterior (Dupuy, 2012). En tanto, para el Archipiélago de Juan Fernández, el binomio isla/continente se ha abordado desde los discursos identitarios de la población local que responde a las claves de insularidad del territorio, en una suerte de oposición al "otro", entendido como el Chile continental (Brinck, 2006). La oposición entre insulares (autodenominados "endémicos") y continentales (llamados "plásticos"), es una relación entre categorías que articulan los discursos de identidades sobre el pasado y el presente, sustentados desde la relación con el exterior (Vanhulst, 2014). En este recorrido sobre la comprensión de la relación isla/continente, las visualidades están escasamente representadas en el repertorio de estudios insulares en Chile. A diferencia de otras islas que han desarrollado una lectura de sí mismas divergente a la mirada continental, como son las aproximaciones oceanizadas emergentes que dialogan con tradiciones humanistas $\mathrm{y}$ ambientalistas, y se expresan en diversas narrativas descentradas del continente, pensando e imaginando las islas como formas de relacionalidad, El Archipiélago de Juan Fernández pareciera fijado al enfoque de los espacios continentes o terrestres, atado a la matriz de pensamiento colonialista que moldea un modo de ver el territorio insular.

En este artículo se analiza el conjunto de 5 imágenes sobre el Archipiélago de Juan Fernández de la colección y de la exhibición permanente sobre el territorio insular de la Región de Valparaíso en el Museo de Historia Natural de la ciudad. Los museos de historia natural han estado bajo el escrutinio por su ligazón con los contextos colonialistas en cuanto proyectos expansionistas eurocentrados en los que el naturalismo decimonónico en un gesto extractivista nutrió las colecciones de piezas biológicas de los museos estadounidenses y europeos, erigiéndose en una epistemología de cuño colonialista. En la actualidad el legado del contexto colonialista se proyecta en que los museos de historia natural aún son vistos como espacios de producción de conocimiento autorizado en el mundo moderno, de modo que la práctica museística contemporánea tiene la marca del papel que desempeñaron en el proyecto colonial (Marks, 2017; Das \& Lowe 2018). Sobre esta herencia emerge la interrogante en relación a las formas en que el pasado se incorpora al ejercicio autoreflexivo del propio museo a partir de sus prácticas curatoriales. El Museo de Historia Natural de Valparaíso como institución estatal participa de la narrativa dominante sobre el territorio insular desde el litoral central de Chile continental, articulando la historia, el conocimiento, tradiciones de pensamiento, vocabulario e imaginería que en términos generales reproducen las representaciones masivas sobre el Archipiélago en circulación y asociadas al consumo cotidiano de imágenes. Así, el museo se inscribe en la construcción de insularidad como práctica históricamente situada de producción de la alteridad desde la distinción isla/continente como marca sobre el territorio, los sujetos, los objetos y las memorias. Los dilemas sobre la construcción de lo insular son compartidos por diversas comunidades en el mundo asentadas en islas y archipiélagos, pero también tienen especificidades que cambian entre épocas y países que aportan con los matices de los estudios archipelágicos (Batongbacal, 1998). Para identificar ejes consistentes que permitan caracterizar las visualidades del museo se desarrolla el análisis de la co-construcción entre lo insular, la ciencia naturalista y la nación en los siglos XIX y XX atendiendo a las imágenes sobre Juan Fernández que están expuestas presencialmente (en sala) y virtualmente (en catálogo digital Surdoc.cl).

\section{DEFINIENDO EL ARCHIPIÉLAGO DE JUAN FERNÁNDEZ}

El Archipiélago de Juan Fernández se encuentra en el Pacífico Sur, a 670 km (365 millas náuticas) del puerto de Valparaíso (Chile), y está compuesto por tres islas (Robinson Crusoe, Alejandro Selkirk y el islote Santa Clara), además del conjunto de islotes de menor tamaño deshabitados que en total alcanzan 99,67 km². En el Archipiélago viven poco más de mil personas con lazos de parentesco cruzados debido a la endogamia, y se dedican principalmente a la pesca sostenida de la langosta local (Jasus frontalis); el resto de la población trabaja en la atención de los servicios públicos y en el área del turismo aventura (buceo, pesca y senderismo). El Archipiélago está situado en el Área Marina Costera Protegida (Decreto 1026 de 2017), reserva que abarca 9.571 hectáreas en las que se concentran especies endémicas. Se trata de territorios subacuáti$\cos$ (maritorio) de ambientes frágiles, por el que cruzan las rutas migratorias de múltiples especies protegidas (ballenas jorobadas, delfín negro, orcas, etc).

Sobre el Archipiélago de Juan Fernández se ha escrito mucho, principalmente de la condición excepcional de su ecosistema (Vargas et al., 2014) reconocido por Unesco como Reserva de la Biósfera (1977). Le sigue en intensidad los relatos mediáticos que promueven el turismo extremo en las islas, los de la búsqueda intermitente del tesoro pirata escondido en alguna cueva (Bertrand, 2007) y los relativos a las formaciones rocosas como monumentos proféticos de los Mayas que originó el programa "La isla apocalíptica" en el History Channel. Las tragedias que recientemente han desincentivado el turismo han copado por momentos la prensa y noticieros, como el maremoto de 2010 que destruyó buena parte de las viviendas de la isla Robinson Crusoe dejando 25 desaparecidos, así como el desplome en el mar de la aeronave de la Fuerza Aérea de Chile en 2011, accidente en el que murieron 21 personas mientras maniobraba para aterrizar en el aeródromo de la Bahía Cumberland.

La literatura y cinematografía sobre el Archipiélago también es abundante, consolidando el estereotipo del náufrago imaginativo 
que sobrevive en una isla solitaria a partir del hecho histórico de abandono del marino escocés Alejandro Selkirk y la invención de su alter ego en el personaje literario de Robinson Crusoe (Brescia, 2005; Derrick, 1981). Los relatos sobre el uso como presidio del Archipiélago de Juan Fernández por la Corona española (Vicuña Mackenna, 1883; Romo 2004) y en el siglo XX (Carmona Ulloa, 2020) completan el inventario de temáticas desde las que se han sedimentado las representaciones, estereotipos y memorias colectivas sobre el Archipiélago.

El peso de Benjamín Vicuña Mackenna con su obra “Juan Fernández. Historia verdadera de la isla Robinson Crusoe" (1883), en la construcción del relato dominante sobre este territorio es ineludible. Vicuña Mackenna inicia su texto con el avistamiento de la isla por él mismo cuando estuvo recluido en 1859, momento que se superpone con el instante en el que el marino español Juan Fernández divisa la isla en el último tercio del siglo XVI, continuando con el repaso de las leyendas y ficciones sobre la supervivencia de Crusoe y Selkirk, para luego volver al uso como cárcel de criminales y disidentes políticos que vivió en carne propia Vicuña Mackenna. El recorrido finaliza con la descripción de la flora, fauna, detalles de la orografía insular y la vida doméstica, para cerrar con los acontecimientos políticos de fines del siglo XIX rondados por el fantasma de la insurrección en las islas como proyección de los conflictos en el continente. Vicuña Mackenna tardó más de veinte años en escribir su obra a partir de la sistematización de textos anteriores y fuentes diversas, rasgo particular de este trabajo devenido en referencia fundamental sobre el Archipiélago de Juan Fernández si se considera que la historiografía sobre este territorio ha estado más bien inmersa en construcciones narrativas globales e inscrita en visiones contemporáneas que recrean y proyectan los aportes de las tradicionales historias generales en una funcionalidad más bien multidisciplinar (Mellado, 2016).

Preocupado por el carácter fundacional del relato histórico del Estado y la nación a construir, Vicuña Mackenna en múltiples escritos cuestionó el afán colonialista europeo y el proyecto expansionista de EEUU sobre Chile (Ubilla, 2020), y en una maniobra que puede resultar algo contradictoria, definió la noción de "coloniaje" republicano en una solución de ruptura con el pasado sombrío bajo la monarquía española (Marrero \& Cinelli, 2019), pero adoptando el proyecto expansionista colonialista para la nueva república ilustrada. La Exposición del Coloniaje (1873) fue la gran narración visual que gestó Vicuña Mackenna para instalar la idea del "coloniaje" en el presente luminoso de autodeterminación del país como la superación del período colonial y la consolidación de la senda del progreso a través de la reinterpretación de un conjunto de posesiones de la élite dominante (objetos funcionales, artísticos y de connotación simbólica) presentados como patrimonio de la nación. Esta operación revela en su narrativa los principios del nuevo coIonialismo interno civilizatorio, que emerge de la ciudad capital y captura todo el territorio nacional. Las obras de Vicuña Mackenna (escritas y curatoriales) son ejemplares en la instalación de una memoria e imaginarios colectivos centralizados sobre la nación y el territorio, los que constituyen una propuesta de cultura visual en tanto establece relaciones entre elementos discursivos, visuales y perceptivos, encarnados en las colecciones y espacios de exhibición como heurística para restringir el repertorio y los modos de lo recordable y lo visible (Faba, 2013).

En manos de Vicuña Mackenna, el Archipiélago de Juan Fernández queda cristalizado como territorio de secretos y enigmas, solitario e inhóspito, que se define como frontera occidental del Chile colonial y republicano, y se opone al continente como metrópoli civilizatoria: La historia íntima de Juan Fernández es la demostración viva de cuán a prisa el hombre civilizado se hace salvaje en la soledad, obedeciendo a irresistible, no cultivado ni jamás domado instinto de su fiera naturaleza (Vicuña Mackenna, 1883:8). Vicuña Mackenna no solo sintetiza una tradición occidental para conceptualizar lo insular, sino también destaca el lugar del Archipiélago en una geopolítica que sitúa su relato en la historia eurocentrada a la que ingresa Chile como república con sus propias colonias de ultramar, recordando que Juan Fernández era para los británicos su isla de Malta del Pacífico (Vicuña Mackenna, 1883:160).

En este itinerario de relatos que definen al Archipiélago, y que transcurre entre narrativas científicas, literarias, mediáticas e históricas, se reconoce la concepción de lo insular coproducida y codeterminada por varios agentes, y sugiere el análisis desde la perspectiva del dispositivo, como un artefacto de poder-conocimiento que convierte los territorios y las culturas en objetos de posesión, conquista y consumo imperiales (Said, 2002). El punto de vista del museo es una de las miradas que también está sujeta a revisión, entendido como dispositivo-exhibicionario (Bennett, 1995), lugar simbólico de la modernidad y del colonialismo en su versión pretérita, y del neocolonialismo en su expresión actual.

En general, las visualidades insulares de Chile se han construido históricamente en el continente, y el MHNV como institución estatal adhiere a una línea argumental sobre las islas ya esbozada en el pasado a través de la historiografía nacional y la literatura, en la que los agentes insulares con capacidad para actuar en la protección, conocimiento y denuncia de la vulnerabilidad de estos territorios se limitan al Estado, la Marina y los científicos situados en el continente. A través de fotografías actuales de la geografía insular y su vegetación, como imágenes predominantes de la exposición permanente del MHNV sobre el Archipiélago Juan Fernández y Rapa Nui, se construye una narrativa basada en relaciones verbovisuales que definen lo insular revelando la geografía escarpada contenida por el mar, como reservas desiertas, carentes de todo tipo de vida y disociadas de las series de fotografías de primeros planos de la vegetación en los que suele verse a un científico examinando plantas in situ. La función de las fotografías es realista y no estético en cuanto persuade sobre la existencia efectiva de lo representado sea la isla como geografía, su flora, fauna o a los mismos científicos.

El papel de la ciencia y los científicos para revelar lo autóctono y por ende el valor de las islas es central en el relato del MHNV sobre los territorios insulares, los que se descubren en su riqueza ante la mirada del especialista que se desplaza desde el continente en un continuo de captura y creación de imágenes que se remonta al siglo XIX y transcurre hasta el presente. De acuerdo a esto, el territorio insular atrajo primero la atención de viajeros y naturalistas carentes de estricta formación científica hasta que irrumpe el botánico sueco Carl Skottsberg, en la primera década del siglo XX, confiriendo autoridad científica -en la que están implicadas las imágenes-sobre el valor de las islas al reconocerlas como escenarios de especies endémicas, apoyado por el transporte de la Marina, y en definitiva del Estado que ejerce su dominio sobre los territorios de ultramar a través de los científicos. 
VISUALIDADES DE LA EXPERIENCIA NATURALISTA INSULAR: MARÍA GRAHAM Y CLAUDIO GAY

En general la exhibición permanente del MHNV sobre la Región de Valparaíso tiene como eje el reconocimiento y valoración de la biodiversidad del litoral central y depresión intermedia de Chile, es decir, se trata de un proyecto museográfico contemporáneo emergente (Hernández y Santacana, 2009) que transcurre entre el litoral central y la zona intermedia hasta la cordillera colocando las piezas biológicas de las colecciones en vívidos dispositivos que representan los viajes de exploración por la región de naturalistas y científicos de los siglos XIX y XX (en tren, batiscafo, corbeta, a pie). De acuerdo al MHNV, se privilegia la dimensión experiencial e interpretativa de los y las visitantes en la aproximación al entorno natural por sobre el acopio de caudales de información de las museografías más convencionales. La apreciación de la naturaleza promovida en el MHNV no residiría solo en el plano cognitivo racional que encarna tradicionalmente la ciencia, sino también en una dimensión poética muy presente en los naturalistas de antaño, la que se intentaría actualizar en esta museografía renovada (Waissbluth, 2014:52). La convergencia entre la sensibilidad estética y la curiosidad científica se sugiere en la exhibición como punto de encuentro sobre el que convergen las imágenes de las islas, que en el marco de significación de la experiencia de conocimiento sobre el territorio insular se propone la distinción entre viajero, naturalista y científico, planteando que la diferencia entre los dos primeros radica en la ausencia de herramientas científicas para producir conocimiento, donde están implicadas la producción de imágenes. Los naturalistas como el francés Claudio Gay y el alemán Federico Johow se caracterizarían en la exhibición como los primeros agentes insulares que se desplazan desde el continente en un viaje largo y a menudo incómodo (MHNV, 2014) para revelar la naturaleza hasta entonces desconocida, recopilando toda la información posible sobre los territorios descubiertos (MHNV, 2014) ejecutando operaciones que anticipan la aproximación científica como describir, dibujar, diseccionar, comparar y medir sobre lo que veían en el medio natural (MHNV, 2014). De esta enumeración de actividades, los viajeros como la inglesa María Graham, sólo registrarían por escrito y en imágenes la vivencia de la sujeta sobre el medio insular de acuerdo a las visualidades que presenta la exhibición.

En la Sala Corbeta, el Archipiélago de Juan Fernández es descrito por naturalistas y viajeros como territorio prometedor para las aspiraciones de apuntalamiento en ultramar de la nación continental. Para Claudio Gay el clima de la isla es enteramente suave i sano... esa diferencia de Santiago (MHNV, 2014), como espacio conquistado para la ciencia del Estado según el alemán Federico Johow, durante mi permanencia en la isla busqué la planta tan disputada i tan interesante para la jeografía vejetal i la alegría que experimenté [al encontrarla] (MHNV, 2014), y como destino idílico para María Graham es la isla más pintoresca que he visto toda formada de grandes rocas perpendiculares y hermosos valles (MHNV 2014).

En este conjunto de apreciaciones sobre Juan Fernández de los paneles de la Sala Corbeta del MHNV, se observa la relación textoimagen centrada en el patrón dicotómico naturaleza/sociedad del paradigma naturalista moderno. Por contraste, el entorno natural de Rapa Nui carecería de valor frente al brillo de su patrimonio cultural asociado a una población viva, mientras que en Juan Fernández se descartarían los vestigios de cultura, pasando por alto a los habitantes pasados y presentes, y sólo se enaltece la naturaleza.
Las imágenes insulares de las narrativas de los museos revelan una visualidad moderna dicotómica naturaleza/sociedad sobre la que se articula la geografía occidental y la diferencia colonial en la tendencia a exaltar el paisaje insular e idealizar las islas pequeñas como modelos paradisíacos, utópicos, biodiversos, vulnerables, turísticos, salvajes. La exaltación idílica de las islas como objeto de goce o como objeto científico queda bajo la misma sospecha que se cierne sobre las estrategias identitarias que suprimen las memorias de las crueldades de la explotación pretérita insular (Sedeño, 2019). El extractivismo, la despoblación y repoblamiento a costa del destierro y el relegamiento desde el continente son parte de la historicidad insular que confronta la visión placentera de las islas desde la distancia de la nave en el mar o desde el litoral. Esta mirada se inscribe en un modelo de representación de la materialidad de los espacios insulares y los océanos como espacio que rodean a los continentes y lo confirma como centro de las comparaciones. Las islas se definen así a partir de la negación ante lo que caracterizaría a los continentes, y así se instituyen como espacios negativos al continente lo que resulta de las estructuras epistémicas y políticas moderno-coloniales. La invisibilización de los gestos neocoloniales sobre las islas, derivados del extractivismo económico neoliberal y de los centros de producción de un discurso académico sobre lo insular exportable al Sur global, es el legado de las mismas estructuras moderno-coloniales de la que son parte los museos de historia natural a nivel global.

Las estampas de Claudio Gay y María Graham sobre Juan Fernández se sitúan en esta directriz participando abiertamente en la creación efectiva del "paisaje insular" desde una mirada estetizante de la naturaleza formulada desde el continente, que siendo dominante deja un margen para la expresión de las relaciones históricas, sociales y políticas isla/continente que se infiltran en el conocimiento y valoración de las islas, franja o borde en el que se vislumbra la población isleña como un actor más de la discusión sobre los territorios insulares.

El trabajo científico de Gay se ha asociado a la justificación de la existencia de la nueva república y la legitimación de la viabilidad económica y social a través de la descripción de los territorios que la conforman, pero la obra concebida inicialmente como historia natural derivó a petición de las autoridades republicanas en historias nacionales (Sagredo, 2009). En el cumplimiento de esta función, Claudio Gay fue transportado en 1832 al Archipiélago en la nave Colo-Colo de la Marina de Chile, y representó visualmente el evento exploratorio insular en la estampa Presidio de la isla de Juan Fernández, la que sintetiza el conocimiento, control y memoria del territorio en el que el Estado chileno debía ejercer su soberanía plena sobre la remota frontera occidental de ultramar.

La estampa (Figura 1) recrea el momento en que un grupo pequeño, de cuatro personas, desembarca de la nave de dos velas en un bote a remos que se aproxima a la orilla de la isla cruzando el mar crispado bajo el cielo nublado y amenazante. En la imagen sobresalen al fondo los enormes murallones de piedra cubiertos de vegetación característicos de la isla Robinson Crusoe, los que circundan el pequeño poblado carcelario yermo, formado por una decena de casas, en el que se observan unas pocas personas en la orilla mirando hacia el barco y al bote que avanza. Así predomina la naturaleza generosa y desconocida que contrasta con el espacio alterado por el avance civilizatorio restringido a un espacio intermedio de control entre el mar y el relieve. El punto de observación de la isla/presido está en el océano, más allá del barco fondeado, 


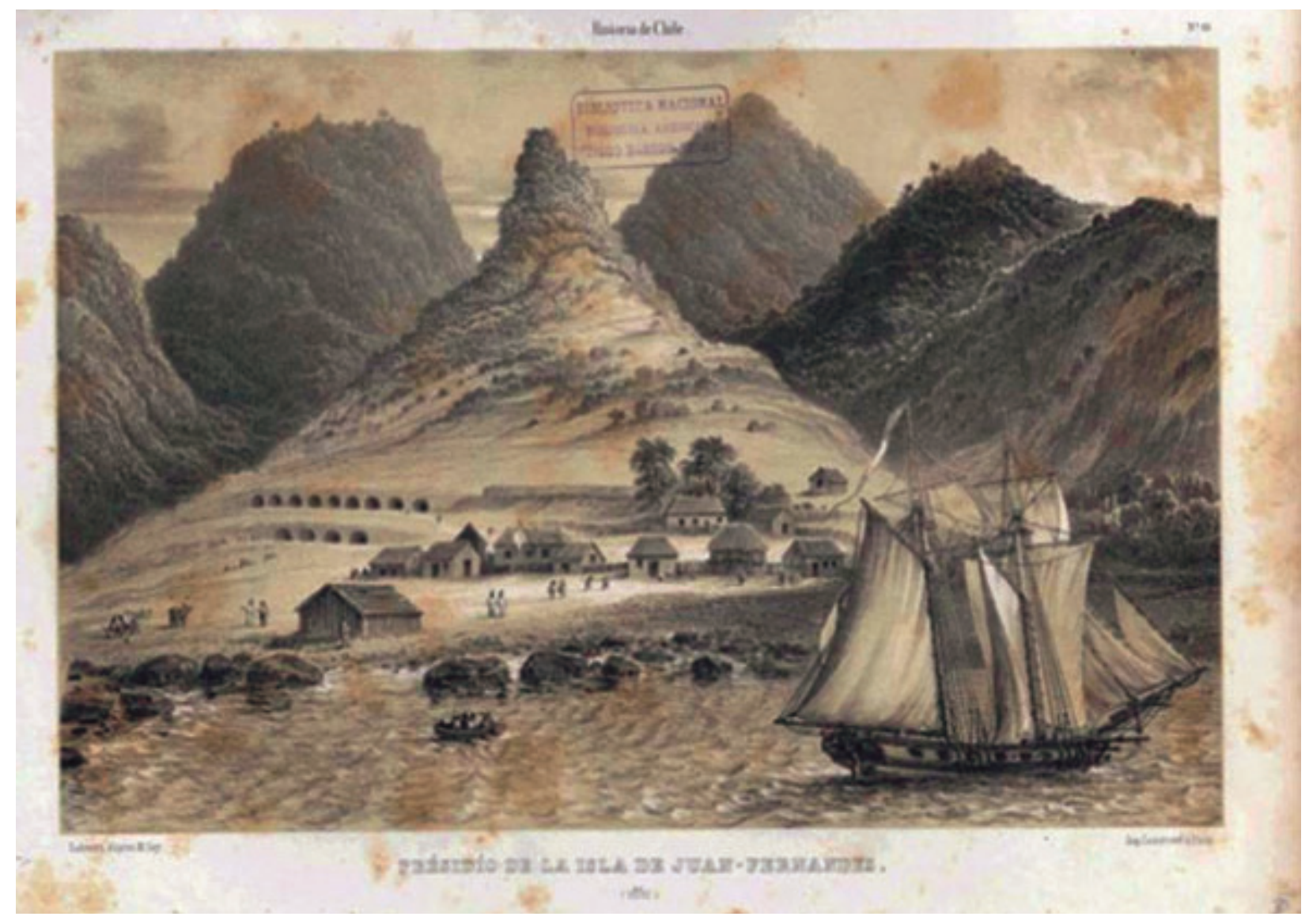

como una visión que se prolonga desde el continente, en la que no pasan desapercibidas 13 cuevas/celdas ubicada al fondo y costado izquierdo del poblado solitario e inhóspito como huellas del doliente pasado reciente colonial. La imagen de la isla sintetiza el relato histórico y científico que no se orienta a la integración territorial de la sociedad a través de una visión dominante sobre el paisaje insular de la nación y su memoria.

María Graham visita el Archipiélago una década antes que Gay (1822) y su primera impresión de admiración del entorno insular contrasta con la visión de las ruinas de una pequeña ciudad (Graham 1822), los vestigios del asentamiento carcelario. En un ejercicio exploratorio del territorio, el paisaje de Graham (Figura 2) revela su lugar de observación, emplazado dentro de la isla, y formando parte de ella transitoriamente. Es así que en el conjunto de Graham la monumentalidad del entorno natural, particularmente los macizos elevados cubiertos por el follaje que abarcan la mitad superior de la composición, acentúan la diferencia de escala que recoge la observadora al estar allí y así consigna visualmente su punto de vista sobre un aspecto central de la experiencia insular. En la estampa se presenta el espacio agreste por el que transcurre la vida cotidiana de la población, sugerida con un par de botes que yacen sobre la orilla, barriles de madera amontonados junto a ellos, postes para atar embarcaciones y una pareja que se desplaza hacia el horizonte escarpado. La rutina apacible y solitaria de los habitantes es parte del paisaje y está flanqueada por el mar como un elemento ligado a la experiencia insular y no a la continental.

Cabe agregar que pasajes del "Diario de mi residencia en Chile", así como su correspondencia privada y bocetos inéditos, dan cuenta de la gran capacidad de Graham en botánica, optando por reemplazar por un dibujo minucioso la planta que no podía extraer para un herbario. A través de acuarelas y dibujos Graham capturó la

> Figura 1. Prisión de la Isla Juan Fernández. Fuente: Gay, 1832. 


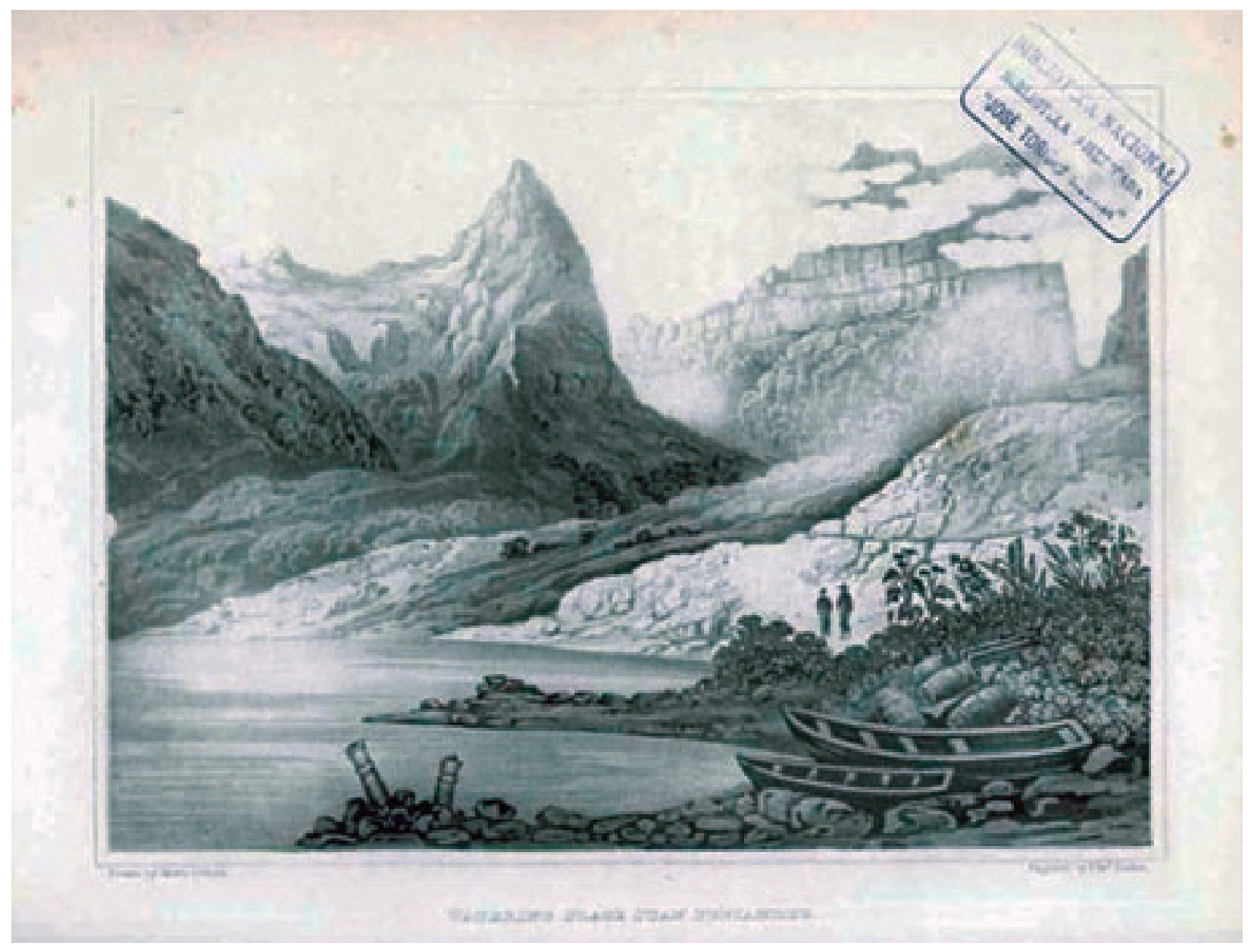

vegetación que contrastaba con su hábitat en el paisaje en cientos de imágenes. Pese a la abundancia de los dibujos, se desconocen las razones por las que Graham omitió los dedicados estudios botánicos de sus propios recuentos de viaje (Manthorne, 2017).

A diferencia de las fotografías que predominan en la exhibición permanente sobre Juan Fernández del MHNV, empleadas en la legitimación del objeto/isla, las estampas de Gay y Graham definen por su parte el paisaje insular en términos no solo científicos, sino también estéticos e identitarios, desde la oposición hombre/naturaleza pero también -en el caso de Graham-superando la dicotomía isla/continente al situar el punto de observación en la isla, relevando los aspectos que significan el paisaje en la vivencia cotidiana y que caracterizan el contexto isleño. Gay y Graham crean paisajes insulares del Archipiélago sujetos al paradigma naturalista cientificista y estatal continental, complementándose mutuamente, pero a la vez tensionan los límites del marco de significados sobre las islas al recoger sutilmente los fragmentos omitidos (agentes, memorias, tiempo, océano) con el que se narra lo insular.

\section{LA REPRODUCCIÓN MECÁNICA DE LAS VISUALIDADES NATURALISTAS}

María Graham recorrió la isla Robinson Crusoe realizando acuarelas en una escala portátil $\left(7 \frac{1}{4} 4 \times 11\right.$ ") que le permitía realizar el bosquejo preliminar del paisaje in situ (Manthorne, 2017). Posteriormente, las acuarelas de Graham se convirtieron en los originales sobre los que se realizaron grabados lineales para fines de reproducción. Esta práctica creciente en el siglo XIX, motivó por ejemplo la traducción al grabado de las obras de Graham por Edward Finden. Del mismo modo, el francés H.Vander-Burch llevó al grabado 


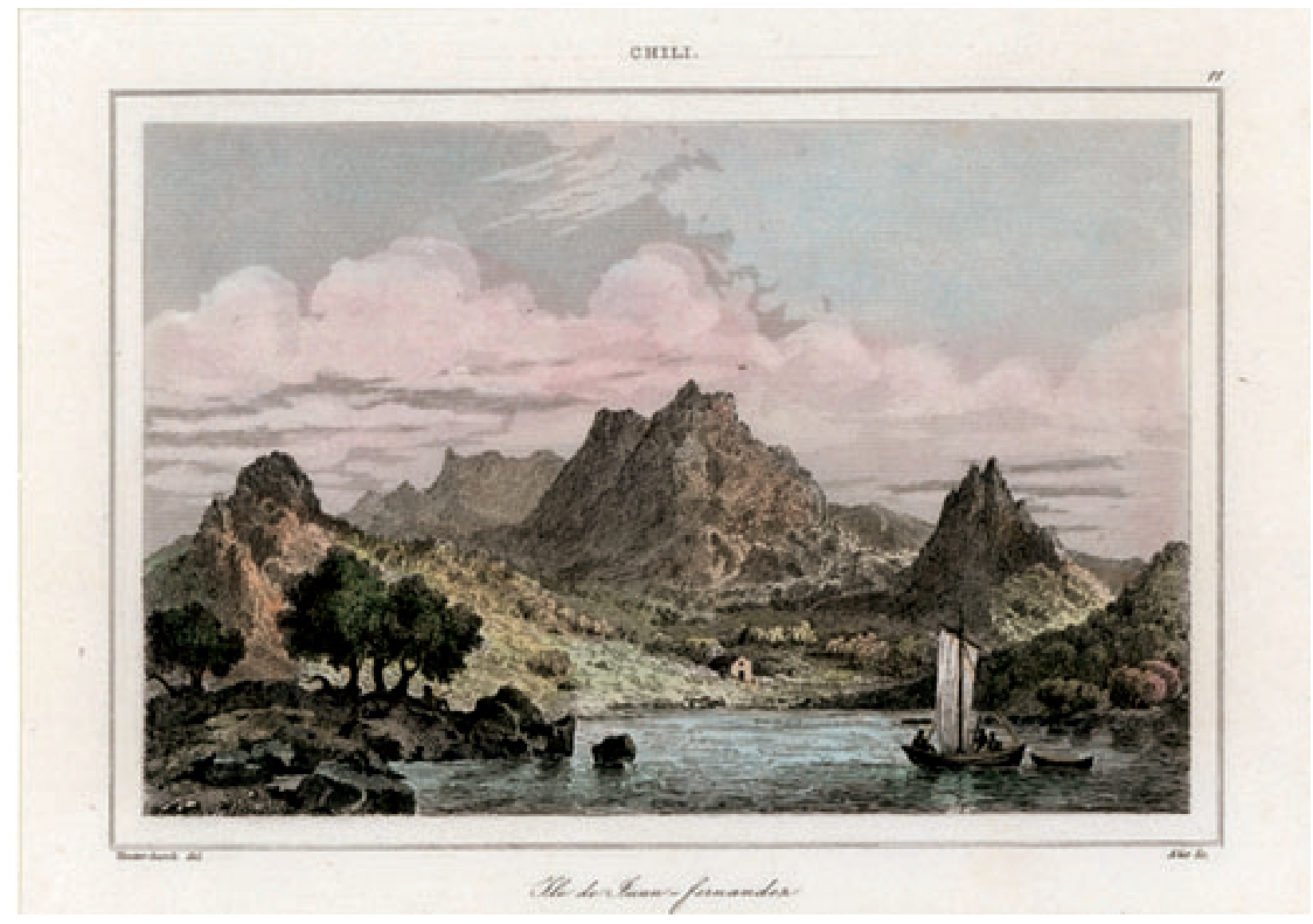

algunos dibujos de Claudio Gay así como de José Gandarillas, en los que la técnica de reproducción permite realzar la monumentalidad en el paisaje (Martínez, 2011). Vander-Burch dibujó en 1840 una vista de Juan Fernández grabada por el francés Alès y luego coloreada a mano, que pertenece a la colección del MHNV (Figura 3) y presenta la misma vista de la Bahía Cumberland dibujada por Gay, pero el punto de observación se encuentra más adentro en el mar y no se distinguen habitantes ni las cuevas de los patriotas. Como en la imagen de Gay y Graham, Vander-Burch destaca los murallones de piedra del fondo, bajo un cielo nuboso, mientras se aproxima a la bahía una embarcación de una sola vela en el que viajan tres personas y arrastra un bote sobre el mar ligeramente ondulante.

En este período pre-fotográfico, los grabados de dibujos, pinturas y acuarelas permitieron ilustrar múltiples libros científicos como "La geografía universal" del geógrafo y escritor anarquista Élisée Reclus, en el que hay una imagen del Monte Selkirk (Figura 4) en la isla Robinson Crusoe grabada por Charles Barbant y Taylor en 1885, parte de la colección del MHNV. Reclus prefería llamar a su obra "La tierra y los hombres", y en ella propone en el texto un contrapunto entre el entorno natural de Juan Fernández en oposición a la geografía europea mientras la imagen funciona confirmando el contraste, como testimonio de la diferencia desde un enfoque eurocentrado. Es así que estas imágenes van conformando un repertorio de visualidades sobre el Archipiélago que empiezan a circular ampliamente y se vuelven dominantes, como la vista del Monte Selkirk que mantiene gran parecido con las fotografías del relieve de Robinson Crusoe tomadas por Carl Skottsberg en el siglo XX. Hay un modo de ver naturalista que se desliza en la prensa como un discurso visual autorizado, y se distancia de las consideraciones estéticas asumiendo las funciones de testimoniar la existencia de lo real atribuidas posteriormente a la fotografía sobre el entorno natural.

> Figura 3. Ille de Juan Fernandez (1840). Fuente: Surdoc.cl (cod. 4-3144). 
Fig 179,-Moesr Sexme, Jeas Fensuxper Inusp.

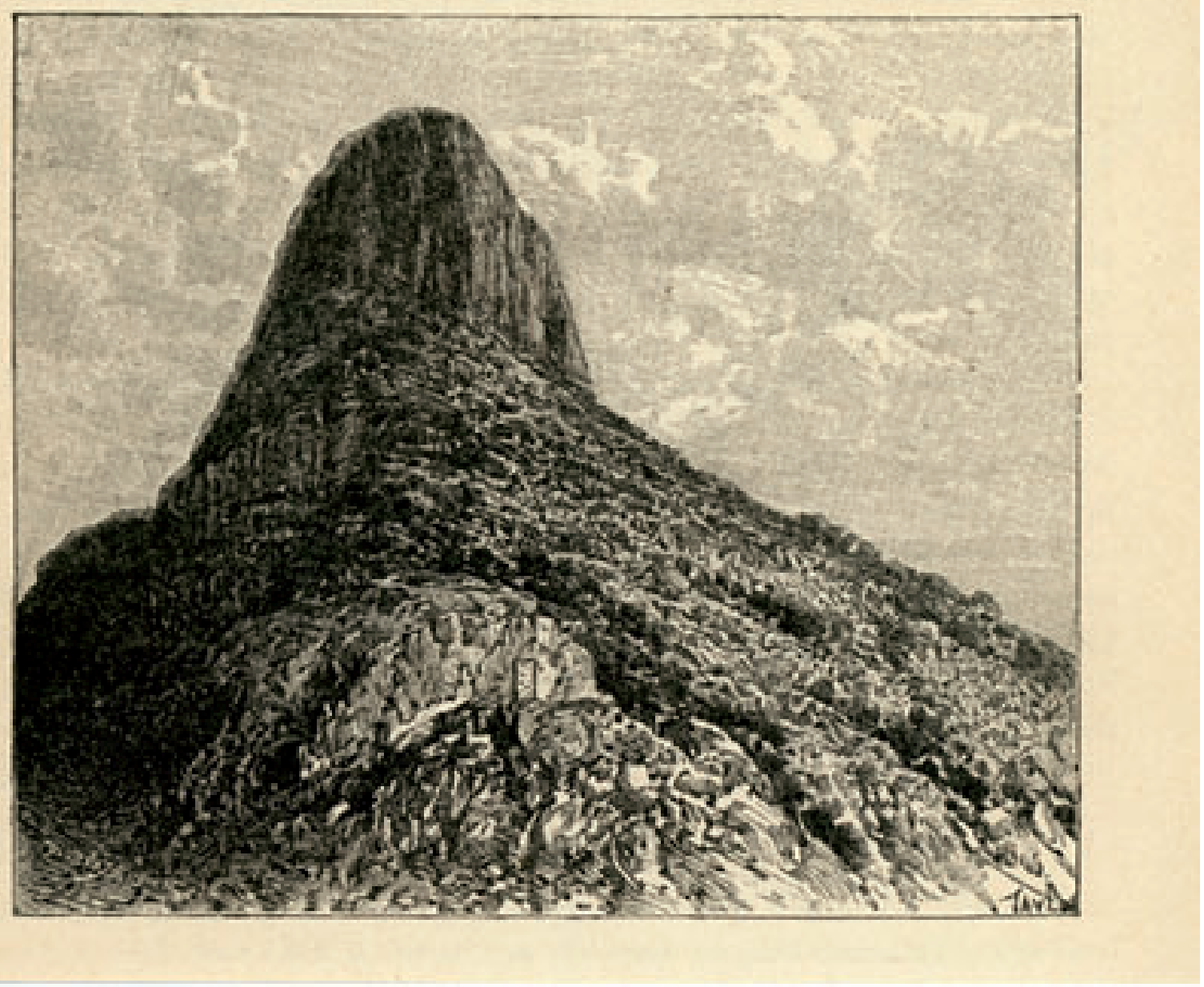

El desarrollo de los periódicos ilustrados a mediados del siglo XIX, tanto en volumen de ejemplares como en extensión geográfica de circulación, impulsó el "reporte pictórico", dibujos que al pasar al soporte del grabado ilustraban las narrativas de los diarios señalando el encaje entre la imagen normalizada por los naturalistas y la prensa que la adopta y difunde masivamente. Se trata del momento de transición en Europa y EEUU en el que la litografía, grabado en madera y la fotografía en sus inicios conforman los modos de reproducción mecánica que fueron moldeando la esfera pública y en ella el repertorio de imágenes estereotipo de distintas geografías, lugares y personas.

El MHNV cuenta con una imagen de Juan Fernández hecha por el artista J.J. Wild, miembro del equipo de exploración que viajó alrededor del mundo en la embarcación británica Challenger ( $\mathrm{Fi}$ gura 5), boceto publicado en The Illustrated London News el 10 de junio de 1876 acompañando la crónica del viaje. El Illustrated London News se le considera el primer periódico que inició el uso de grabados y fotografías para ilustrar crónicas y reportajes, incidiendo de manera relevante en la conformación de la opinión pública británica sobre la envergadura del imperio Victoriano. La crónica relata la detención en Juan Fernández donde la expedición obtuvo gran cantidad de material para estudios científicos -geográficos, hidrográficos, meteorológicos, físicos, botánicos, zoológicos y antropológicos- lo que bien valió el coste de la expedición. Juan Fernández es descrita para el público británico como el antiguo escondite de los bucaneros, ahora arrendado por el Gobierno chi- 


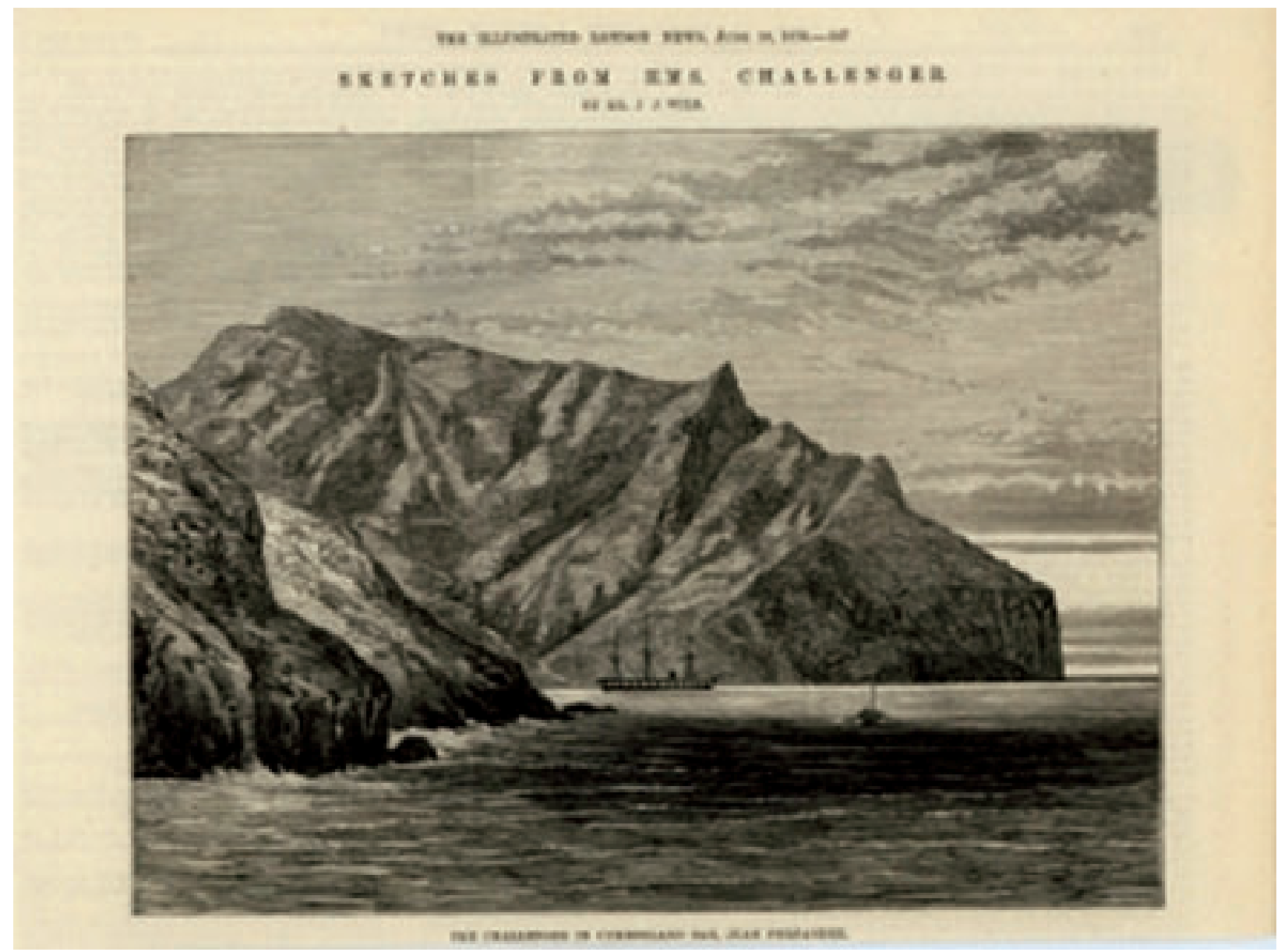

establece la correspondencia entre el pasado pirata de despojo y ocultamiento en la isla y el presente científico de sustracción de recursos naturales realizado por la expedición, mediado por el uso fraudulento del Estado chileno del siglo XIX que paga un arriendo por el usufructo del territorio. El boceto de J.J. Wild sintetiza los tres momentos con los que se define a Juan Fernández en la crónica y presenta en primer plano y al fondo los murallones rocosos de la isla mientras el Challenger avanza por el costado en dirección a la bahía de Cumberland para quedar oculta a la vista del observador que se encuentra en altamar.

Cabe señalar que posterior al viaje del Challenger, el empresario minero inglés John Thomas North, conocido como "el rey del salitre", pagó crónicas y reportajes sobre Chile que estimularan la inversión extranjera, y financió en 1889 un viaje de exploración en el vapor Galicia de la Pacific Steam Navigation Company entre Punta Arenas y los territorios mineros del norte del país, travesía que se relata en numerosas crónicas y reportajes con imágenes grabadas. The Illustrated London News expone una práctica discursiva singular en que las imágenes y las palabras permiten la producción de verdad(es) comprometidas con un complejo conjunto de otros discursos de mediados del siglo XIX, entre ellos el científico (Sinnema, 2019).

\section{CONCLUSIONES}

La aproximación a la relación isla/continente remite en principio a la agenda temática y problemática de los saberes geográficos que fluctúan entre la relación antagónica y la complementaria entre ambas nociones. Desde este punto de vista, la comprensión de la 
isla como unidad alude insoslayablemente a la relación con el continente, con lo costero, lo que permite cuestionar la idea dominante de "aislamiento" implícita en su propia denominación. El recorrido imagen-texto expone el binomio isla/continente menos ligado a las historias insulares concretas y más ajustado a las concepciones científicas continentales que a las particularidades del terreno insular. La visión naturalista, que implica el saber geográfico, aporta con esquemas interpretativos que han trascendido sus orígenes en las ciencias naturales occidentales, de modo que al transitar por diversos contextos textuales, institucionales y disciplinares, extienden sus sentidos hacia otras áreas de la cultura (Lois, 2013). Así, las variadas geografías insulares se pueden dilucidar desde el análisis del repositorio múltiple y diverso de la relación insular/ continental como dualidad conceptualizada y operacionalizada en un acervo visual que es parte de la expansión colonizadora de Occidente hacia el resto del mundo. La isla excede y complementa al continente (Edmond \& Smith, 2003). Es así que las narrativas insulares en sus relaciones verbo-visuales, lejos de ser periféricas en los procesos de conformación y consolidación de los nacionalismos y el Estado-nación moderno, desempeñan un rol significativo en la comprensión de la formulación de imaginarios nacionales (Doods \& Royle, 2003:495). La demanda por rearticular las visualidades y representaciones que han actuado colonizando también el imaginario (Gruzinksi, 2003) delata para el caso de los territorios insulares como han sido también capturados por los "laboratorios de imágenes" interculturales de la colonialidad, integradas a la cultura visual global.

\section{BIBLIOGRAFÍA}

Batongbacal, J. (1998). Defining Archipelagic Studies. En Batongbacal, J. (ed.). Archipelagic Studies: Charting New Waters. Quezon City: University of the Philippines Printery, 183-94.

Bennett, T. (1995). The Exhibitionary Complex. En The Birth of the Museum. History, Theory, Politics. London: Routledge.

Bertrand, S. (2007). Antonio y el tesoro de Juan Fernández. Editorial Amanuta.

Brescia, M. (2005). Selkirk / Robinson: el mito. A tres siglos del solitario en Isla Robinson Crusoe (1704-2004). Santiago: Marenostrum.

Brinck, G. (2006). Memorias insulares. Archipiélago Juan Fernández. Valparaíso: Puntángeles.

Campbell, R. (1999). La cultura de la Isla de Pascua: mito y realidad. Santiago: Andrés Bello.

Carmona Ulloa, E. (2020). Islas-cárcel, castigo a la transgresión. Crónicas de dos siglos de violencia política. Santiago: Mapocho Press.

Das, S., \& Lowe, M. (2018). Nature read in black and white: Decolonial approaches to interpreting natural history collections. Journal of Natural Science Collections, 6, 4-14.

Derrick, C. (1981). Juan Fernández. La Isla de Robinson Crusoe. En Salvat, J. (ed.). Pueblos de la tierra. Razas, ritos, costumbres. Tomo II. Barcelona: Salvat.

Dodds, K. \& Royle, S. A. (2003). The historical geography of islands. Introduction: rethinking islands. Journal of Historical Geography, 29(4), 487-498.
Dupuy, F. (2012). Seeking a new paradise for mankind: Rockwell Kent in Tierra del Fuego and the creation of a new national image for Chile. Art Logie. Dossier Thématique - Image de la nation: art et nature au Chili (3). Capturado de: http:// cral.in2p3.fr/artelogie/spip.php?article150 (Último acceso 6 mayo 2021).

Edmond, R., \& Smith, V. (Eds.). (2003). Islands in History and Representation. London: Routledge.

Espindola Gerhardt, L. (2018). Palimpsesto de Karukinka. Tras las huellas de la forma urbana en la Isla Grande de Tierra del Fuego, Argentina-Chile. Identidades: territorio, proyecto, patrimonio, (7), 3-24.

Faba, P. (2013). Cultura visual y memoria en el Chile del siglo XIX. Redefiniendo el coloniaje a través de su exhibición. Revista de teoría del arte, (24), 13-33.

Ferrando, C.; Piergiova, C. y Fuentes, M. (2011). La Compañía Explotadora de Isla de Pascua: patrimonio, memoria e identidad en Rapa Nui. Santiago: Escaparate.

Galilea, M. (2015). Isla de Pascua y la crisis ecológica en la poesía de Pablo Neruda: Ruinas de la imagen insular. Acta literaria, (50), 103-131.

Galindo, Ó. (2000). El imaginario insular antiutópico en la poesía chilena reciente. Revista Austral de Ciencias Sociales, (4), 175-185.

Gay, C. (1832) Presidio de la Isla Juan Fernández, 1832. Disponible en Memoria Chilena, Biblioteca Nacional de Chile http://www.memoriachilena.gob.cl/602/w3-article-99703.html (Último acceso 6 mayo 2021).

Graham, M. (1822). Watering place Juan Fernández, 1822. Disponible en Memoria Chilena, Biblioteca Nacional de Chile http://www.memoriachilena.gob.cl/602/w3-article-70445.html (Último acceso 6 mayo 2021).

Graham, M. (2019). Diario de mi residencia en Chile en el año 1822. Madrid: Penguin.

Gruzinski, S. (2003). La guerra de las imágenes. De Cristóbal Colón a "Blade Runner" (1492- 2019). México: Fondo de Cultura Económica.

Hernández, Francesc X. y Santacana, Joan (2009). Las museografías emergentes en el espacio europeo occidental. Hermes (1), 220-226.

Horlent, L. M., Malizia, M., \& Van Aert, P. (2020). Tierra del Fuego: imaginarios sobre la extremidad en el sur de América Latina entre los siglos XVIII y XX. Revista de la Red Intercátedras de Historia de América Latina Contemporánea: Segunda Época, (12), 79-103.

Hau'ofa, E. (1994). Our Sea of Islands. The Contemporary Pacific, 6(1), 148-161.

Lois, Carla. (2013). Isla vs. continente: Un ensayo de historia conceptual. Revista de geografía Norte Grande, (54), 85-107

Mansilla Torres, S. (2006). Chiloé y los dilemas de su identidad cultural ante el modelo neoliberal chileno: la visión de los artistas e intelectuales. Alpha (23), 9-36. 
Mansilla Torres, S. (2007) Hay un dios que todo lo compra: Identidad y memoria de Chiloé en el siglo XXI. Revista Austral de Ciencias Sociales (12), 145-158.

Manthorne, K. (2020). Female Eyes on South America: Maria Graham in Brazil. En Cartographic Expeditions and Visual Culture in the Nineteenth-Century Americas. London: Routledge, 147-166.

Marks, J., 2017. Is Science Racist? St. Ives: Polity.

Marrero, A. \& Cinelli, N. (2019) ¿Cómo creer que eso es la España que todos amamos? Etimología e intencionalidad del término coloniaje: historia del arte, historia y literatura. Tempus Revista en Historia General (9),1-22.

Martínez, J.M. (2011). El paisaje chileno. Itinerario de una mirada. Santiago: Museo Histórico Nacional.

Mellado Villena, M. J. (2016). La frontera del oeste. El Archipiélago de Juan Fernández y su constitución fronteriza (17501800): aspectos locales de un conflicto imperial (Doctoral dissertation, Universidad Finis Terrae (Chile) Facultad de Humanidades y Comunicaciones).

Montiel Vera, D. (2003). Chile-Chiloé: una transición de dos caras. Chiloé: crónicas de un mundo insular. Puerto Montt: Dimar.

Museo de Historia Natural de Valparaíso (2014). Exhibición permanente Sala Corbeta.

Pérez López, M. A. (2011). Rosabetty Muñoz: entre el agua y la furia. América sin Nombre. (16), 113-120.

Romo Sánchez, M. (2004). La prisión de los patriotas chilenos en Juan Fernández. Santiago: Apostrophes.

Sagredo, R. (2009). Geografía y nación: Claudio Gay y la primera representación cartográfica de Chile. Estudios geográficos, 70(266), 231-267.

Said, E. (2002). El Orientalismo. Barcelona: Random House Mondadori.

Sedeño Guillén, K. (2019). Introducción: Islas (des) imaginadas: de la matriz moderno-colonial al caribe archipelágico. Visitas al Patio, 13(2), 10-21.

Sinnema, P.W. (2019). Dynamics of the Pictured Page: Representing the Nation in the "Illustrated London News". London: Routledge.

Ther Ríos, F. (2008). Prácticas cotidianas e imaginarios en sociedades litorales: el sector de Cucao, Isla Grande de Chiloé. Chungará, 40(1), 67-80.

Ther-Ríos, F. (2020). Others ruralities/understanding Chiloé: Proposals for a recomposition based on a new model of territorial epistemology. Journal of Rural Studies, 78, 372-377.

Ubilla Espinoza, Lorena (2020). Pensamiento y acción americanista en los liberales chilenos: la propuesta de Benjamín Vicuña Mackenna, 1862-1868. Estudios filológicos, (65), 77-96.

Vanhulst, J. (2014). Amenazas y perspectiva para la preservación de la biodiversidad en el Archipiélago de Juan Fernández. Revista Chilena de Estudios Regionales. Chile, 2 (2).
Vargas, R., Smith-Ramírez, C., González, C., \& Fernández, M. (2014). Reserva de la Biosfera Archipiélago Juan Fernández: endemismo para conservar. Reservas de la Biosfera de Chile: Laboratorios para la Sustentabilidad, 17, 126143.

Vicuña Mackena, B. (1883). Juan Fernández. Historia verdadera de la Isla de Robinson Crusoe. Santiago: Rafael Jover Editores.

Waissbluth, Verónica (2014). Museo de Historia Natural de Valparaíso. Un viaje inolvidable. Revista PAT (61), 48-55. 